\title{
INTERACTION OF AU WITH GaSb AND ITS IMPACT ON THE FORMATION OF OHMIC CONTACTS*
}

\author{
A. Piotrowska, E. Kamińska, T. Piotrowski, S. Kasjaniuk, \\ M. Guziewicz
}

Institute of Electron Technology, Al. Lotników 32/46, 02-668 Warszawa, Poland

\section{S. Gierlotka}

Unipress, Polish Academy of Sciences, Sokołowska 29, 01-142 Warszawa, Poland

X.W. Lin, Z. Liliental-Weber, J. Washburn

Materials Science Division, Lawrence Berkeley Laboratory

University of California, Berkeley, CA 94720 , USA

\section{AND S. KWIATKOWSKI}

A. Sołtan Institute for Nuclear Studies, Hoża 69, 00-681 Warszawa, Poland

Interfacial reactions between $\mathrm{GaSb}$ and $\mathrm{Au}$ were studied by Rutherford backscattering, X-ray diffraction, and cross-sectional transmission electron microscopy. Evaluation of the extent to which the GaSb substrate decomposes was of primary concern. The results give evidence that the reaction takes place even at temperatures as low as $180^{\circ} \mathrm{C}$. High reactivity of gold towards $\mathrm{GaSb}$ revealed by this study demonstrates that Au-based metallization is not a good candidate for device quality ohmic contacts to GaSb-based devices.

PACS numbers: 73.40.Ns

Recently there has been an increasing interest in GaSb-based semiconductors. Due to their small band gap, they are a natural material of choice for many applications in the infrared, while the small effective masses of light holes and conduction electrons, unique band offsets and surface properties makes them particularly challenging candidates for novel quantum-effect devices. However, few studies have been published on ohmic contacts to these materials $[1,2]$. The obtained results show that low Schottky barrier heights for metals on GaSb do not

*This work was supported by the State Committee for Scientific Research (Republic of Poland), grant No. 9-8026-92-03. 
favor significantly lower contact resistances. Moreover, little is known as yet about the microstructure of metal-GaSb interfaces under heat treatment.

In this work we report on electrical properties and microstructure of $A u$ and AuZn contacts to $p$-GaSb. We selected gold as a contact metal, because gold-based metallizations provide the lowest contact resistances to GaAs and InP, and thus they remain the most commonly used in the technology of ohmic contacts to semiconductor devices.

Experiments were performed on (100) oriented $p$-type GaSb doped with Ge to a concentration of $1.3-5 \times 10^{18} \mathrm{~cm}^{-3}$. Prior to deposition of the contact materials, the samples were degreased in hot organic solvents, and etched in a solution of $\mathrm{CH}_{3} \mathrm{COOH}-\mathrm{HNO}_{3}-\mathrm{HCl}-\mathrm{Br}_{2}$, followed by a rinse in isopropyl alcohol. $100 \mathrm{~nm}$ thick elemental $\mathrm{Au}$ and $\mathrm{Au}(20 \mathrm{~nm}) / \mathrm{Zn}(10 \mathrm{~nm}) / \mathrm{Au}(60 \mathrm{~nm})$ metallization were deposited by evaporation in oil-free vacuum system. Capless and $\mathrm{SiO}_{2}$-capped contacts were annealed in flowing $\mathrm{H}_{2}$ at temperatures up to $400^{\circ} \mathrm{C}$ for $3 \mathrm{~min}$.

Evaluation of the extent to which the GaSb substrate decomposes under above conditions was of primary concern. This was studied by the combined use of $2 \mathrm{MeV} \mathrm{He}{ }^{+}$Rutherford backscattering (RBS), X-ray diffraction (XRD), and cross-sectional transmission electron microscopy (XTEM). We quantified losses of volatile components by applying the Cr-collector method [3]. Electrical characterization involved the measurements of $I-V$ characteristics, and of the specific contact resistance. For electrical measurements, contact windows $(\phi=200 \mu \mathrm{m})$ were patterned using the photoresist lift-off technique.

As-deposited $p$-GaSb/Au contacts exhibited ohmic behavior and were characterized by specific contact resistance $r_{\mathrm{c}}$ of $1 \times 10^{-4} \Omega \mathrm{cm}^{2}$. Upon annealing at $300^{\circ} \mathrm{C}, r_{\mathrm{c}}$ decreased to the value of $1 \times 10^{-5} \Omega \mathrm{cm}^{2}$. Addition of $\mathrm{Zn}$ into the metallization did not improve the contact resistance.

RBS spectra for samples before and after annealing are shown in Fig. 1. According to RBS analysis, no intermixing takes place between $\mathrm{GaSb}$ and metallization during heat treatment up to $250^{\circ} \mathrm{C}$. Annealing at $300^{\circ} \mathrm{C}$ drastically changes the contact microstructure. First, the RBS spectrum for a contact capless-annealed (Fig. 1a) reveals that both gallium and antimony are located at the sample surface. Secondly, as inferred from the computer simulation (RUMP) of RBS spectra, a $750 \mathrm{~nm}$ thick reacted region, of a composition of 50 at.\% of $\mathrm{Au}$ and 25 at.\% of $\mathrm{Ga}$ and $\mathrm{Sb}$ at the surface, was formed. At $350^{\circ} \mathrm{C}$ the surface concentration of $\mathrm{Ga}$ and $\mathrm{Sb}$ increases up to 35 at.\%, and the reacted layer spreads out to $850 \mathrm{~nm}$. The RBS spectra for contacts processed with $\mathrm{SiO}_{2}$ cap (Fig. 1b) are almost like those for uncapped ones, indicating that $\mathrm{SiO}_{2}$ cap does not prevent from the decomposition of $\mathrm{GaSb}$. No loss of $\mathrm{Sb}$, as measured by $\mathrm{Cr}$-collector method, appeared in our samples even when annealed at $400^{\circ} \mathrm{C}$.

Figure 1c compares RBS spectra for as-deposited, and uncapped and cap-annealed $\mathrm{GaSb} / \mathrm{Au}(\mathrm{Zn})$ contacts. While the interfacial reaction between $\mathrm{Au}(\mathrm{Zn})$ metallization and $\mathrm{GaSb}$ is less pronounced that in the case of elemental Au, here also $\mathrm{Ga}$ and $\mathrm{Sb}$ are found at the sample surface. The $\mathrm{SiO}_{2}$ cap slightly suppresses the decomposition of semiconductor substrate. XRD analysis indicates that contacts annealed above $300^{\circ} \mathrm{C}$ contain three phases: $\mathrm{AuSb}_{2}$ and two unidentified so far phases, resultant probably from the $\mathrm{Au}-\mathrm{Ga}$ interaction. 

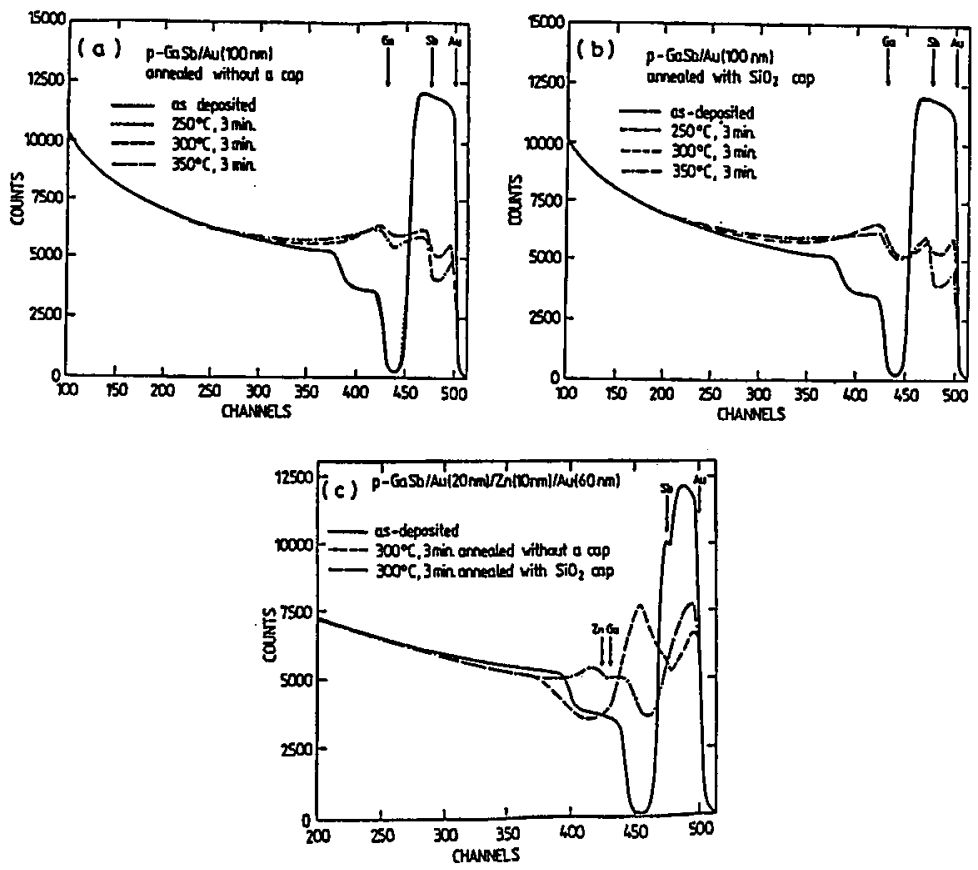

Fig. 1. $2 \mathrm{MeV}{ }^{4} \mathrm{He}^{+}$RBS spectra of as-deposited and annealed contacts: (a) capless-annealed $\mathrm{GaSb} / \mathrm{Au}$ contact, (b) cap-annealed $\mathrm{GaSb} / \mathrm{Au}$ contact, (c) GaSb/Au(Zn) contact.

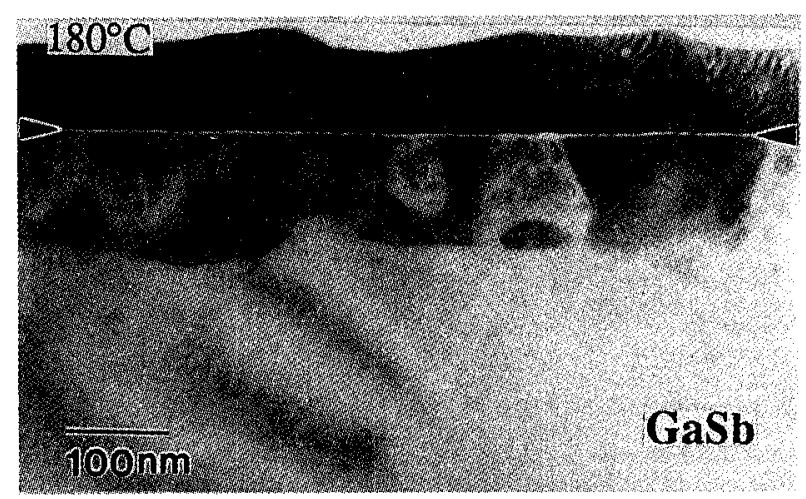

Fig. 2. A cross-sectional TEM image of an $\mathrm{GaSb} / \mathrm{Au}(\mathrm{Zn})$ contact annealed at $180^{\circ} \mathrm{C}$ for $3 \mathrm{~min}$.

Cross-sectional TEM analysis gives evidence of an interfacial reaction during heat treatment below $300^{\circ} \mathrm{C}$. For a $180^{\circ} \mathrm{C}$ annealed sample, shown in Fig. 2, a reacted layer about $100 \mathrm{~nm}$ thick below the metal contact is clearly seen (interface is marked by arrows). The original oxide surface layer on $\mathrm{GaSb}$ remains intact after reaction. 
In conclusion, the results of our metallurgical studies give evidence that the reaction between $\mathrm{Au}$ or $\mathrm{Au}$-based metallization and $\mathrm{GaSb}$ takes place even at temperatures as low as $180^{\circ} \mathrm{C}$. Above $250^{\circ} \mathrm{C} \mathrm{Ga}$ and $\mathrm{Sb}$ appear at the surface of the contact. In contrast to GaAs or InP, where enhanced sublimation of arsenic or phosphorus was observed during annealing, and the use of a capping layer substantially restrained the interfacial reaction, here only trace amounts of antimony were found in $\mathrm{Cr}$ collectors.

High reactivity of gold towards GaSb revealed by this study demonstrates that $\mathrm{Au}$-based metallization is not a good candidate for device quality ohmic contacts to GaSb-based devices.

\section{References}

[1] J.B.B. Oliveira, C.A. Olivieri, J.C. Galzerani, A.A. Pasa, F.C. de Prince, J. Appl. Phys. 66, 5484 (1989).

[2] A.G. Milnes, M. Ye, M. Stam, Solid State Electron. 37, 37 (1994).

[3] A. Piotrowska, E. Kamińska, S. Kwiatkowski, A. Turos, J. Vac. Sci. Technol. 73, 4404 (1993). 